\title{
СПЕЦИФИКА ПСИХОЛОГИЧЕСКИХ ТРУДНОСТЕЙ И РЕСУРСОВ ПЕДАГОГОВ СПЕЦИАЛЬНОГО И ИНКЛЮЗИВНОГО ОБРАЗОВАНИЯ
}

Исслед. выполнено при поддержке Российского фонда фундаментальных исследований проект №20-013-00435A.

Тихонова И.В., Адеева Т.Н., Плюснина А. А. (Костромской государственный университет, Кострома, Россия) inn.007@mail.ru, adeeva.tanya@rambler.ru, plyusnina-anyuta2015@yandex.ru

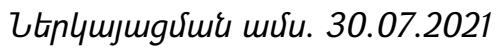

9pupunuर्uाध uर्रu. 23.08.2021

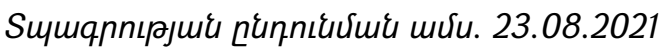

В статье представлены результаты эмпирического исследования психологических трудностей и ресурсов педагогов, работающих в условиях инклюзивного и специального образования. В исследовании принимали участие 50 педагогов. Использовались авторская анкета «Исследование психологических трудностей и ресурсов педагогов», опросник оценки ресурсов совладания со стрессом (CRIS), методы математической статистики. Выявлено преобладание эмоциональных и мотивационных трудностей в работе всех специалистов, обучающих детей с ОВЗ. В профиле психологических ресурсов педагогов обнаружены достоверные отличия ( $\mathrm{p} \leq 0.05)$ по показателям уверенности, контроля напряжения, структурированности профессиональной деятельности, направленности на себя. Ресурсами педагогов инклюзивного образования являются уверенность и структурирование. Им помогает справляться с трудными жизненными ситуациями вера в собственные возможности и умение управлять временем и энергией, строгое планирование и целеполагание. Педагоги в специальных школах достоверно отличаются от своих коллег такими ресурсами как контроль и направленность на себя. Им помогает совладать с трудными ситуациями возможность высказывать свое мнение, критиковать. Но также они используют релаксацию, контроль мыслей.

Ключевые слова: психологические ресурсы, психологические трудности, профессиональный стресс педагогов, инклюзивное и специальное образование, обучаюшиеся с ограниченными возможностями здоровья.

DOI: https://doi.org/10.46991/SBMP/2021.4.2.349

Проблематика исследования профессионального стресса, механизмов и факторов его развития является остро актуальной для российских и зарубежных исследователей XXI века, что связано с современными изменениями, 
затрагивающими условия, содержание труда, профессиональные требования, приводящими к высокому уровню интенсификации профессиональной деятельности. По мнению Леоновой А.Б. «это обусловлено не только усилением влияния специфичных для разных видов труда требований и интенсивных рабочих нагрузок, но и необходимостью действовать в быстро изменяющихся ситуациях с высокой степенью неопределенности с повышенным риском потери стабильного места работы, материального и социального статуса» [3, с. 64]. Однако, не смотря на большую практическую и теоретическую ценность исследований механизмов и условий стрессогенности разных профессий, влияний профессионального стресса на успешность в профессии, все чаще исследователи фокусируются на фракторах позволяющих сохранять продуктивность, способностях личности противостоять неадаптивным стрессовым состояниям. Акцент в исследованиях смещается в сторону изучения психологических ресурсов профессионала.

Под индивидуальными психологическими ресурсами мы понимаем физиологические, когнитивные, личностные, социально-психологические (принятие себя и других, уверенность в себе, умение распознавать потенциально стрессовые ситуации и контролировать уровень стресса и др.) качества и свойства субъекта (в основном, им осознаваемые), обладающие возможностью к накоплению/расходованию, развитию и видоизменению, а также материальную обеспеченность, к которым субъект обращается в моменты стресса и сложных жизненных ситуаций в целях совладания с ними [4, с.110]. Хазова С.А. уточняет, что «в качестве ресурса могут выступать и черты, и способности при условии, что в результате концептуализации опыта они оцениваются как полезные, дающие преимущества, как источник дополнительных сил» [6, с.85].

Исследования показывают, что профессии типа «человек-человек» характеризуются высоким уровнем стрессогенности и напряженности. Чуева Е. Н. отмечает, что при этом основным фактором стресса является субъективная оценка профессиональной ситуации, однако так же значение имеют сложность решаемых задач, дефицит знаний и умений, отсутствие возможности самостоятельного планирования выполнения работ, необходимость жесткого следования предписанным правилам и инструкциям, отсутствие разнообразия в работе [7, с. 169].

Педагогическая профессия входит в группу профессий с большим присутствием стресс-факторов, что предъявляет повышенные требования к такой интегральной комплексной характеристике как стрессоустойчивость [1, с. 47]. В качестве основных структурных компонентов стрессоустойчивости педагога определены следующие: психологическая и эмоциональная уравновешенность, стремление к саморазвитию и самопознанию, умение ставить цели и достигать результата, коммуникативные навыки, активность, ассертивное 
поведение и терпимость [2, с. 65]. Развитие системы образования, подразумевающее ориентацию на толерантность и готовность принять и обучать любого ребенка, внедрение ценностей и реальных практик инклюзии связано с возникновением новых профессиональных трудностей педагогов, повышающих риски профессиональной напряженности и стрессогенности [5]. Определение объективных и субъективных трудностей педагогов приводит к необходимости поиска ресурсов, способствующих эфрективному решению профессиональных задач и повышению уровня профессиональной адаптации.

В настоящее время существуют противоречивые мнения и доказательства относительно эффективности реализации образовательных потребностей детей с ОВЗ в условиях специального или инклюзивного обучения. Одним из факторов выбора условий обучения является личность педагога и его готовность к работе с особыми детьми, умение справляться со специфическим трудностями профессиональной деятельности, ресурсы их преодоления.

С целью изучения профессиональных трудностей и психологических ресурсов педагогов реализующих инклюзивные формы обучения детей с ОВ3 и педагогов специальных образовательных учреждений, нами было проведено пилотажное исследование. Выборка состояла из 50 педагогов, все респонденты женщины, 25 человек работают в инклюзивном образовании, 25 человек - в специальном образовании. 20 педагогов имеют стаж работы с детьми с 0В3-5 и менее лет, 30 педагогов-более 5 лет. В исследовании использованы: авторская анкета «Исследование психологических трудностей и ресурсов педагогов» (А. А Плюснина., И.В. Тихонова), опросник оценки ресурсов совладания со стрессом - CRIS (разработан К.Б. Матени, адаптирован А.В. Махначом и Ю.В. Постыляковой), методы математической статистики (дескриптивная статистика, вычисление U-критерия Манна-Уитни). 


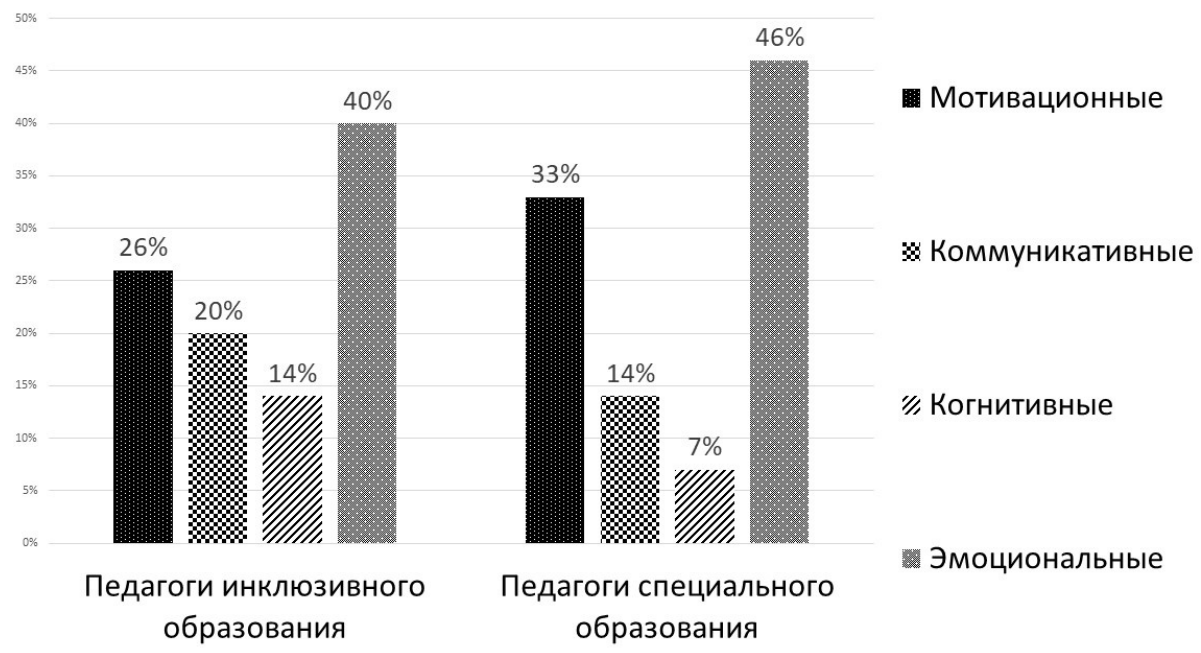

Рисунок 1. Психологические трудности педагогов инклюзивного и специального образования

Исследование трудностей профессиональной деятельности и ресурсов их преодоления с помощью опросного метода выявило (рисунок 1), что в целом профиль представленности трудностей идентичен у педагогов, работающих в специальных учреждениях и у педагогов, обучающих детей с ОВ3 в общеобразовательных школах. Однако, можно отметить, что педагоги специальных школ чаще указывали трудности эмоционально-мотивационного типа, в то время как специалисты инклюзивного образования по сравнению со своими коллегами отмечали проблемы коммуникативно-когнитивного типа. Лидирующую позицию в ответах педагогов занимают трудности эмоционального типа - эмоциональное напряжение, эмоциональное истощение, негативные эмоции. Для преодоления эмоциональных трудностей педагоги чаще всего используют индивидуальные, физические и творческие ресурсы: отдых и уединение, сон, переключение на другой вид деятельности (хобби, танцы, рисование, спорт, чтение, рукоделие). Более трети от всех указанных педагогами трудностей занимают мотивационные проблемы: трудности самореализации, несоответствие ожиданиям, формальность деятельности, неоцененность значимости работы. В качестве ресурсов преодоления данных трудностей педагоги указывают социально-ориентированные (поддержка семьи и друзей, социальное взаимодействие и общение с коллегами, получение обратной связи от родителей и коллег), когнитивные (обучение, получение новой информации и чтение специальной литературы), редко используют индивидуальные 
ресурсы (умение распределять нагрузку). На третьем месте по выраженности находятся трудности коммуникативного типа: проблемы общения с коллегами (недопонимание, расхождение во мнениях, трудно договориться) и сложности коммуникации с родителями, редко встречаются трудности взаимодействия с детьми с ОВ3. Данный вид трудностей чаще встречается в группе специалистов инклюзивного образования. В качестве ресурсов для преодоления этих трудностей специалисты используют индивидуально-личностные ресурсы: гибкость, толерантность, готовность к диалогу, оптимизм, а также когнитивные ресурсы (знание психологии). Реже всего педагоги отмечали когнитивные трудности, но с большей частотой они встречались в ответах педагогов инклюзивных классов: недостаток знаний и опыта в работе с детьми с ОВ3, недостаток знаний о методах и методиках обучения и работы с детьми с ОВ3. В качестве ресурсов в данных случаях они используют индивидуально-когнитивные (обучение и чтение специальной литературы) и социальные (общение с коллегами).

Далее нами были проанализированы результаты характеризующие индивидуальные ресурсы и их специфику в группах педагогов специального и инклюзивного образования (таблица 1), получены значимые различия по шкалам «Уверенность», «Контроль напряжения», «Структурирование», «Направленность на себя» $(p<0,05)$.

Таблица 1.

Показатели ресурсов совладания со стрессом в исследуемых группах $(n=25)$.

\begin{tabular}{|l|c|c|c|c|}
\hline \multicolumn{1}{|c|}{ Шाкалы } & $\begin{array}{c}\text { Педагоги } \\
\text { инклюзивного } \\
\text { образования } \\
\text { (n=25) }\end{array}$ & $\begin{array}{c}\text { Педагоги } \\
\text { специального } \\
\text { образования } \\
(\mathbf{n}=25)\end{array}$ & $\mathbf{U}$ & $\mathbf{P}$ \\
\cline { 1 - 3 } & Mean & Mean & & \\
\hline Уверенность & 32,5 & 30,1 & 148,5 & 0,001166 \\
\hline Социальная поддержка & 37,0 & 36,5 & 289,0 & 0,651310 \\
\hline Контроль напряжения & 54,9 & 60,3 & 57,5 & 0,000001 \\
\hline Структурирование & 30,0 & 26,1 & 126,0 & 0,000217 \\
\hline Физическое здоровье & 33,8 & 29,7 & 221,00 & 0,070919 \\
\hline Направленность на себя & 31,2 & 37,1 & 0,0000 & 0,000000 \\
\hline
\end{tabular}


Результаты показывают, что в целом все педагоги обладают достаточным уровнем уверенности, которая выступает в качестве ресурса преодоления трудностей. Однако, педагоги, работающие с детьми с ОВ3 в общеобразовательных школах, имеют более высокую выраженность данного ресурса $(U=148,5 ; \quad p=0,001)$, они чувствуют себя более способными, контролирующими и компетентными, чем их коллеги из специальных школ. Так же они отличаются более выраженным ресурсом «Структурирование» ( $U=126,0$; $\mathrm{p}=0,002$ ), способностью управлять ресурсами (временем и энергией), умеют планировать и устанавливать цели, приоритеты, собственные усилия.

Педагоги из специальных школ показали достоверно более высокую выраженность такого ресурса как «Контроль напряжения» $(U=57,5 ; p=0,000)$, что говорит об успешном использовании таких способностей как контроль мыслей, погружение в себя, релаксация и прочее, которые помогают им преодолеть трудные ситуации. Для данной группы респондентов также характерна большая степень выраженность ресурса «Направленность на себя» $(\mathrm{U}=0,000 ; \mathrm{p}=0,000)$, чем для их коллег из общеобразовательных школ. Соответственно при преодолении трудных жизненных ситуаций свобода выражения мнений, оценок, чувств и желаний, способность говорить от своего имени, отказывать, получать компенсации при несправедливости, способность выражать противоположное мнение и конструктивную критику имеет для них эфрфект и выступают как полезные.

Обобщая полученные результаты, мы можем охарактеризовать специфику профрессиональных трудностей $и$ ресурсов педагогов специального и инклюзивного образования:

1. Все педагоги, работающие с детьми с ОВЗ, чаще всего предъявляют трудности эмоционального и мотивационного типа: эмоциональное напряжение, истощение, трудности самореализации, неоцененность и разочарование. Для преодоления эмоциональных трудностей используются ресурсы индивидуально-личностного типа: физические и творческие, для совладания с мотивационными трудностями привлекаются социально ориентированные ресурсы.

2. Педагоги, оказывающие сопровождение обучающихся с особыми образовательными потребностями в инклюзивном образовании, также, как и их коллеги, испытывают прежде всего профессиональные трудности эмоционального и мотивационного типа, но чаще предъявляют проблемы коммуникативного $и$ когнитивного типа: испытывают сложности во взаимодействии с коллегами и родителями, чувствуют недостаток опыта и знаний. Специфическими психологическими ресурсами педагогов инклюзивного образования являются уверенность и структурирование. Им помогает справляться с трудными жизненными 
ситуациями вера в собственные возможности и умение управлять временем и энергией, строгое планирование и целеполагание.

3. Педагоги специальных школ достоверно отличаются от своих коллег такими ресурсами как контроль и направленность на себя. Им помогает совладать с трудными ситуациями возможность высказывать свое мнение, критиковать. Но также они используют релаксацию, контроль мыслей.

\section{Литература}

1. Бергис Т.А., Кривуля Ю.С. Проблема профессионального стресса педагогов в условиях современной образовательной системы.// Карельский научный журнал. 2020. Т. 9 . № 1 (30). с. 47-49.

2. Визитова С.Ю. Особенности стрессоустойчивости педагога и психологические ресурсы ее повышения. // Психология образования в поликультурном пространстве. 2010. Т. 2. № 2. с. 62-67.

3. Леонова А.Б. Комплексные психологические технологии управления стрессом и оценка индивидуальной стресс-резистентности: опыт интеграции различных исследовательских парадигм//Вестник Московского университета. Серия 14: Психология. 2016. № 3. С. 63-72

4. Махнач А. В., Лактионова А. И., Постылякова Ю. В. Роль ресурсности семьи при отборе кандидатов В замещающие родители // Психологический журнал. 2015. Т. 36, № 1. с. 108-122.

5. Тихонова И.В., Шипова Н.С., Адеева Т.Н., Иванова Е.А. Психологическое сопровождение школьников С ограниченными возможностями здоровья: потребности участников инклюзивного образовательного процесса. // Вестник Костромского государственного университета. Серия: Педагогика. Психология. Социокинетика. 2017. № 4. с. 184-190.

6. Хазова С. А., Дорьева Е.А. Ресурсы субъекта: теория и практика исследования. Кострома: КГУ им. Н. А. Некрасова, 2012. 230 с.

7. Чуева Е.Н. Специфика проявления профессионального стресса у представителей социономических профессий// Вестник Краунц. Серия «Гуманитарные науки». 2012. № 2 (20). с. 165-174. 


\section{THE SPECIFICS OF PSYCHOLOGICAL DIFFICULTIES AND RESOURCES OF TEACHERS OF SPECIAL AND INCLUSIVE EDUCATION}

Tikhonova I.V., Adeeva T. N., Plyusnina A. A. (Kostroma State University, Kostroma, Russia)

Working with children with disabilities is stressful, requires a lot of emotional, mental costs, resources to overcome professional stress. The article presents the results of an empirical study of psychological difficulties and resources of 50 teachers working in inclusive and special education. The author's questionnaire "Research of psychological difficulties and resources of teachers", the questionnaire of assessment of resources of coping with stress (Copying Resources Inventory for Stress - CRIS), methods of mathematical statistics were used. The predominance of emotional and motivational difficulties in working with children with disabilities was revealed. In the profile of psychological resources of teachers, significant differences were found $(p \leq 0.05)$ in terms of confidence, stress control, structuring of professional activity, self-orientation. The specific resources of teachers of inclusive education are confidence and structuring. They are helped to cope with stress by faith in their own abilities and the ability to manage time and energy, planning and goal setting. Teachers in special schools significantly differ from their colleagues with the resources "control" and "self-orientation". They are helped to cope with difficult situations by the opportunity to express their opinion, to be independent, to criticize. They also use such methods as relaxation, thought control.

Keywords: psychological resources, psychological difficulties, inclusive and special education, professional stress of teachers 